\title{
Synthesis of Chiral Porous Coordination Polymer That Shows Structural Transformation Induced by Guest Molecules
}

\author{
Takashi Kitao, ${ }^{a}$ Yuta Tokunaga, ${ }^{a}$ Daiki Umeyama, ${ }^{a}$ Cho Rong Kim, ${ }^{a}$ Takashi Uemura, ${ }^{* a, b}$, and \\ Susumu Kitagawa ${ }^{* a, c}$
}

a Department of Synthetic Chemistry and Biological Chemistry, Graduate School of Engineering, Kyoto University, Katsura, Nishikyo-ku, Kyoto 615-8510, Japan. Fax: +81-753-2732; Tel: +81-753-2733; E-mail: uemura@ sbchem.kyoto-u.ac.jp

${ }^{\mathrm{b}}$ CREST, Japan Science and Technology Agency (JST), 4-1-8 Honcho, Kawaguchi, Saitama 332-0012, Japan. E-mail: uemura@sbchem.kyoto-u.ac.jp

'Institute for Integrated Cell-Material Sciences (WPI-iCeMS), Kyoto University, Yoshida, Sakyo-ku, Kyoto 606-8501, Japan. E-mail: kitagawa@icems.kyoto-u.ac.jp

\begin{abstract}
We report the synthesis of a new chiral porous coordination polymer $\left[\mathrm{Zn}_{2}\left\{(\mathrm{R})-5,5^{\prime}-\mathrm{BDA}\right\}_{2}(\mathrm{dabco})\right]_{n}$ - $\operatorname{DMF} \quad\left(5,5^{\prime}\right.$-BDA $=$ 2,2'-dihydroxy-1,1'-binaphthalene-5,5'-dicarboxylic acid, dabco = 1,4-diazabicyclo[2.2.2] octane). This compound had one-dimensional (1D) channels which were occupied by DMF molecules. The hydroxyl groups on the surface of the channels acted as DMF interactive sites. Removal of DMF from the pores resulted in an amorphous solid. However, the apohost underwent a structural (amorphous-to-crystalline) transformation in response to the addition of guest molecules with amide groups. Interestingly, the observed degree of crystallinity was different for chiral amides, depending on the stereoisomer used.
\end{abstract}

Keyword: porous coordination polymer; paddlewheel; chiral recognition 


\section{Introduction}

Recently, porous coordination polymers (PCPs) or metal-organic frameworks (MOFs), which are built up from the self-assembly of metal ions with organic ligands, have emerged as a unique class of nanoporous materials ${ }^{1-3}$. Compared with conventional inorganic materials such as zeolites and activated carbons, PCPs can be synthesized in milder conditions, which allows the rational design of novel functional materials. PCPs have highly regular nanopores that can be utilized for gas storage, separation, sensing, ion transport, and polymerization ${ }^{4-8}$. A particularly interesting area in this field is the synthesis of homochiral PCPs and their potential applications, including enantioselective catalyst, separation, nonlinear optical, and ferroelectric properties ${ }^{9-11}$.

One of the most reasonable strategies in designing homochiral PCPs is to combine a metal-containing nodes and chiral organic bridging ligands ${ }^{12}$. Tanaka et al reported the synthesis of a two-dimensional (2D) chiral coordination polymer $\left[\mathrm{Cu}_{2}\left\{(\mathbf{R})-5,5^{\prime}-\mathrm{BDA}\right\}_{2}\left(\mathrm{H}_{2} \mathrm{O}\right)_{2}\right] \cdot \mathrm{MeOH} \cdot 2 \mathrm{H}_{2} \mathrm{O}(\mathbf{1}$; $5,5^{\prime}$-BDA = 2,2'-dihydroxy-1,1'-binaphthalene-5,5'-dicarboxylic acid) ${ }^{13} .5,5^{\prime}$ '-BDA have axial chirality to form a chiral environment in frameworks. The 2D layers are stacked in an A-B-A sequence where the layers are offset, blocking open channels in the square grids. We took a so-called "pillaring strategy" to synthesize a 3D framework ${ }^{14,15}$. The structure of $\mathbf{1}$ shows paddlewheel coordination which consists of binuclear metal clusters in which two metal ions are bridged by four dianions to form a square-planar motif ${ }^{16,17}$ (Fig. 1). Thus, coordination of appropriate pillar ligands to metal ions in the axial positions produces a 3D framework from $\mathbf{1}$.

In this work, we describe the synthesis of a novel chiral PCP based on binuclear paddlewheel unit. For the construction of the porous framework, we employed two methods: the first approach is preparation of a 2D layer followed by mixing with 1,4-diazacyclo[2.2.2] octane (dabco) as the pillar ligand (sequential reaction) ${ }^{16}$. The second approach is concurrent mixing of the metal ion, dabco, and (R)-5,5'-BDA (one-pot reaction) ${ }^{13}$. The synthesized PCP had 1D channels where hydroxyl groups were arranged and interacted with DMF molecules. Solvent exchange experiments indicated that guest molecules with an amide moiety could maintain the crystal structure of framework. Removal of DMF from the pores led to an amorphous solid. The amorphous-to-crystal transformation of dehydrated PCP was invoked by chiral molecules with an amide bond. Interestingly, the degree of crystallinity was changed, depending on which stereoisomer was used.

\section{Experimental}

\subsection{Materials}

All reagents and chemicals used were obtained from commercial sources, unless otherwise noted. 5,5'-BDA, 1, and methyl D-pyroglutamate were prepared according to previously described methods. ${ }^{13,18}{ }^{1} \mathrm{H}-\mathrm{NMR},{ }^{13} \mathrm{C}-\mathrm{NMR}$, IR, and ESI-MS data of 5,5'-BDA and methyl D-pyroglutamate were included in supplementary material.

\subsection{Measurement}


Single-crystal X-ray diffraction measurement was performed at $283 \mathrm{~K}$ with a Rigaku AFC10 diffractometer with Rigaku Saturn Kappa CCD system equipped with a MicroMax-007 HF/VariMax rotating-anode X-ray generator with confocal monochromatized Mo $\mathrm{K} \alpha$ radiation. Data were processed by a direct method(SIR97) and refined by full-matrix least-squares refinement using the SHELXL-97 computer program. The hydrogen atoms were positioned geometrically and refined using a riding model. X-ray powder diffraction (XRPD) data were collected on a Rigaku RINT 2000 Ultima diffractometer with $\mathrm{CuK} \alpha$ radiation. The infrared spectra were measured employing a Thermo Scientific Nicolet iS5. ${ }^{1} \mathrm{H}$ and ${ }^{13} \mathrm{C}$ NMR spectra were obtained using a JEOL A-500 spectrometer operating at $500 \mathrm{MHz}$. The orbitrap mass spectrometer (Thermo Fisher Scientific) equipped with an ESI source was used.

\subsection{Preparation}

\subsubsection{Preparation of $\mathrm{PCP}$ with $\mathrm{Cu}^{2+}$}

In the sequential reaction, 2D layer $\mathbf{1}$ was prepared in advance according to the published method ${ }^{9}$. Subsequently, 1(44mg, $0.09 \mathrm{mmol})$ were added to dabco $(20 \mathrm{mg}, 0.18 \mathrm{mmol})$ in mixed solvents of $\operatorname{DMF}(3.25 \mathrm{ml}), \mathrm{MeOH}(1.2 \mathrm{ml})$, and toluene $(0.6 \mathrm{ml})$. The resulting mixture was heated under solvothermal condition at $140{ }^{\circ} \mathrm{C}$ for 8 hours.

In the one-pot reaction, (R)-5,5'-BDA(100mg, $0.27 \mathrm{mmol}), \mathrm{Cu}\left(\mathrm{NO}_{3}\right)_{2} \cdot 3 \mathrm{H}_{2} \mathrm{O}(72 \mathrm{mg}, 0.42 \mathrm{mmol})$, and dabco $(28 \mathrm{mg}, 0.25 \mathrm{mmol})$ were added together to mixed solvents of $\operatorname{DMA}(2.0 \mathrm{ml})$, and $\mathrm{MeOH}(3.0 \mathrm{ml})$. The resulting mixture was heated under solvothermal condition at $135{ }^{\circ} \mathrm{C}$ for 48 hours.

\subsubsection{Preparation of PCP with $\mathrm{Zn}^{2+}$}

(R)-5,5'-BDA(744mg, 2.0mmol), $\mathrm{Zn}\left(\mathrm{NO}_{3}\right)_{2} \cdot 6 \mathrm{H}_{2} \mathrm{O}(304 \mathrm{mg}, \quad 1.0 \mathrm{mmol})$ and dabco $(112 \mathrm{mg}$, $1.0 \mathrm{mmol}$ ) was added to DMF, and the slurry was stirred at room temperature for 5 hours. After the white precipitate was filtered, the solution was heated at $100{ }^{\circ} \mathrm{C}$ for 2 days to afford single crystals $\left[\mathrm{Zn}_{2}\left\{(\mathrm{R})-5,5^{\prime}-\mathrm{BDA}\right\}_{2}(\mathrm{dabco})\right]_{n} \cdot \mathrm{DMF}(\mathbf{2} \cdot \mathrm{DMF})$ which were suitable for single crystal X-ray diffraction measurement (yield $78 \%$ ). IR spectrum $\left(\mathrm{cm}^{-1}\right)$ : 2929, 1665, 1622, 1575, 1557, 1506, 1464, 1436, 1387, 1255, 1220, 1173, 1150, 1092, 1059, 1017, 924, 839, 815, 785.

\subsection{Guest exchange}

2.DMF was immersed in a variety of solvents, such as dimethylacetamide (DMA), dimethylacrylamide (DMAA), acetone, acetonitrile, chloroform, 2-propanol, methanol, tetrahydrofuran (THF), benzene, and toluene. The mixture was left for 3 hours, replacing the solvent with flesh one every 1 hour.

\subsection{X-ray crystallography}

The data was treated with the SQUEEZE routine in PLATON to correct reflection intensities, corresponding to disordered solvent molecules. Crystal data of $\left[\mathrm{Zn}_{2}\left\{(\mathrm{R})-5,5^{\prime}-\mathrm{BDA}\right\}_{2}(\text { dabco })\right]_{n} \cdot \mathrm{DMF}$ (2.DMF) are summarized in Table 1. Further crystallographic details for the structure reported in this 
paper can be obtained from the Cambridge Crystallographic Data Center (www.ccdc.cam.ac.uk/conts/retrieving.html, E-mail: deposit@ccdc.cam.ac.uk) on quoting the depository numbers CCDC 1007454 for $\mathbf{2}$. DMF.

\section{Results and discussion}

\subsection{Synthesis and description of crystal structure}

The axial sites of $\mathrm{Cu}_{2}$ paddlewheel units in $\mathbf{1}$ are occupied with $\mathrm{MeOH}$ and/or $\mathrm{H}_{2} \mathrm{O}$ molecules. Thus, 3D frameworks can be synthesized by insertion of proper pillar ligands at the axial sites. We synthesized 2D layer $\mathbf{1}$, and then exchanged with dabco at the axial position of $\mathrm{Cu}^{2+}$ ions by a heterogeneous reaction between $\mathbf{1}$ and dabco following the sequential method. After heating $\mathbf{1}$ and dabco in mixed solvents, a green powder was obtained. We compared the XRPD pattern of the green powder with that of $\left[\mathrm{Cu}_{2}\left(4,4^{\prime} \text {-biphenyldicarboxylate }\right)_{2}(\mathrm{dabco})\right]_{\mathrm{n}}(\mathbf{3})$ to confirm the crystal structure of the product ${ }^{19}$. The distance between the carboxyl group at 1 and 4 positions of (R)-5,5'-BDA was similar to that of 4,4'-biphenyldicarboxylic acid. Therefore, the product was expected to have the almost identical structure to 3 . In fact, the product showed a peak at $2 \theta=5.6^{\circ}$, corresponding to the diffraction peak of 3 at $2 \theta=5.8^{\circ}$ which was likely derived from (100) plane (Fig. S1). However, because of the low crystallinity of the product, we could not identify the exact crystal structure. For

the determination of dabco incorporated into the framework, we measured solution ${ }^{1} \mathrm{H}-\mathrm{NMR}$ after dissolving the product in $0.05 \mathrm{M} \mathrm{Na}_{4}$-EDTA deuterium oxide. ${ }^{1} \mathrm{H}$-NMR spectrum of the solution indicated that the mole ratio of dabco to carboxylic linker was 0.1 which was smaller than the ideal ratio of 0.5 . The insertion of dabco between the layers might be difficult probably because of the strong interlayer packing. The small amount of pillar ligand would result in the low crystallinity.

Next, we attempted to synthesize the PCP by the one-pot reaction, however, heating a DMF solution of all components together also gave a low crystalline product. Crystallinity of compounds could not be improved by changing the experimental conditions, such as temperature $\left(110{ }^{\circ} \mathrm{C}-\right.$ $\left.160{ }^{\circ} \mathrm{C}\right)$ and solvent (MeOH, toluene, DMF, and DMA).

$\mathrm{Zn}$ ions can form a paddlewheel unit, hence, pillared-layer type PCPs with an identical structure to that of the $\mathrm{Cu}$ ion can be synthesized from $\mathrm{Zn}$ ion ${ }^{20}$. In addition, due to the mild Lewis acidity, $\mathrm{Zn}$ ions form a weak coordination bond with ligands, which would allow slow kinetics of nucleation and crystal growth ${ }^{21}$. To obtain a single crystal with high purity we conducted the one-pot reaction of $\mathrm{Zn}$ ion, (R)-5,5'-BDA, and dabco.

Here we heated DMF solution of $\mathrm{Zn}\left(\mathrm{NO}_{3}\right)_{2}, 5,5^{\prime}$-BDA, and dabco. The solution was left at $100{ }^{\circ} \mathrm{C}$ for 2 days, giving the crystalline product $\left[\mathrm{Zn}_{2}\left\{(\mathrm{R})-5,5^{\prime}-\mathrm{BDA}\right\}_{2}(\mathrm{dabco})\right]_{n} \cdot \mathrm{DMF}(2 \cdot \mathrm{DMF})$. The structure of $\mathbf{2}$. DMF could be determined by single-crystal X-ray diffraction. The framework of $\mathbf{2}$ is composed of binuclear $\mathrm{Zn}_{2}$ units with a paddle wheel structure, which are bridged by (R)-5,5'-BDA dianions to form a undulating $2 \mathrm{D}$ layer $\left[\mathrm{Zn}_{2}\left\{(\mathrm{R})-5,5^{\prime}-\mathrm{BDA}\right\}_{2}\right]$ with a cavity of dimensions $8.0 \times$ 14.0 $\AA$ (Fig. 3). The DMF molecules are trapped to hydroxyl moieties of (R)-5,5'-BDA in the 
cavities $(\mathrm{O}(\mathrm{DMF})-\mathrm{O}$ (hydroxyl $)=2.5 \AA$ ). As expected, the axial sites of the $\mathrm{Zn}_{2}$ paddle wheels are occupied by dabco, which act as pillars to extend the 2D layers into a 3D structure with 1D channel along the c-axis. XRPD pattern of bulk prepared sample were very similar to the simulated one based on single-crystal structure, ensuring the high phase purity (Fig. 2).

\subsection{Structural transformation}

In the nanochannels of 2, DMF molecules interact with the hydroxyl groups, which are highly ordered on the surface of the channels. To evaluate the interaction between DMF and hydroxyl groups, we carried out IR measurements of $2 \cdot \mathrm{DMF}$ in a region corresponding $\mathrm{C}=\mathrm{O}$ stretching of DMF. Compared with neat DMF $\left(v_{\mathrm{C}=\mathrm{O}}=1675 \mathrm{~cm}^{-1}\right)$, DMF accommodated in the channels of 2 showed clear peak shifts toward lower wavenumber $\left(v_{\mathrm{C}=\mathrm{O}}=1665 \mathrm{~cm}^{-1}\right)$, because of a hydrogen bond formation between carbonyl group of DMF and hydroxyl group of 2 (Fig 4).

Removal of DMF by heating $2 \cdot \mathrm{DMF}$ at $130^{\circ} \mathrm{C}$ for 15 hours under reduced pressure resulted in the amorphous state. The XRPD patterns for the amorphous compound (2') are shown in Fig 2. This crystalline-to-amorphous transformation is accompanied by a loss of DMF molecules in the channels. However, when 2' was immersed in DMF, it reverted to the original crystalline phase $\mathbf{2}$, which is observed by XRPD measurement (Fig 2). This transformation did not occur in the other solvents without amide groups (acetone, chloroform, and $\mathrm{MeOH}$ ), which suggests the formation of hydrogen bonds between guest and host is an important key to determine amorphous-to-crystalline transformation.

We investigated the guest-dependence on the structural transformation behavior. 2.DMF was immersed in various solvents to exchange DMF molecules. After filtration, the adducts were dissolved in $0.05 \mathrm{M} \mathrm{Na}_{4}$-EDTA deuterium oxide. ${ }^{1} \mathrm{H}$-NMR measurements of the solutions ensured quantitative exchange of DMF molecules $(<1 \mathrm{wt} \%)$. XRPD measurements showed that DMA and dimethylacrylamide (DMAA), both having an amide group could maintain the structure of $\mathbf{2}$, in contrast, acetone, acetonitrile, chloroform, 2-propanol, $\mathrm{MeOH}$, tetrahydrofuran, benzene, and toluene collapsed or changed the structure of 2 (Fig. S2). The obtained results suggested that guest molecules that have an amide moiety stabilized the structure through hydrogen bonding.

\subsection{Chiral recognition}

Addition of methyl D- and L-pyroglutamate with amide moiety (Fig. 5) to 2' led to the original XRPD patterns of 2. Interestingly, a difference in the peak intensity was observed between 2.D-isomer and 2. L-isomer. The crystallinity of 2-D-isomer seemed to be higher, comparing with that of 2. L-isomer (Fig. 6). The degree of crystallinity was estimated to be $15.9 \%$ for $\mathbf{2}$-D-isomer and $3.2 \%$ for $\mathbf{2}$ - L-isomer using the background substraction method in Materials Studio ${ }^{22}$ (Fig. S3).

Recognition of chiral molecules plays an important role in the production of wide range of pharmaceuticals, agricultural chemicals ${ }^{23}$. Chiral PCPs have attracted considerable attention because of their potential applications in chiral recognition ${ }^{9,10,24}$. It was demonstrated that chiral recognition 
of PCPs was attributed to the difference of accessibility of a chiral molecule to the interaction sites between D- and L-isomer by single crystal X-ray diffraction measurement ${ }^{24}$. Due to the chirality of 2 derived from 5,5'-BDA, we presumed that the amorphous-to-crystalline transformation was affected by which stereoisomer was used.

\section{Conclusion}

We successfully synthesized a novel chiral porous coordination polymer, $\left[\mathrm{Zn}_{2}\left\{(\mathrm{R})-5,5^{\prime}-\mathrm{BDA}\right\}_{2}(\mathrm{dabco})\right]_{n} \cdot \mathrm{DMF}$ (2-DMF), from the one-pot reaction of all components. The crystal structure of $\mathbf{2}$. DMF was identified by single crystal X-ray diffraction measurement. The hydroxyl groups, which were highly ordered on the surfaces of the channels, interacted with DMF molecules. After removal of DMF molecules, 2 was changed to the amorphous solid (2') that underwent a structural (amorphous-to-crystalline) transformation in response to the incorporation of guest molecules with an amide moiety. In addition, the degree of crystallinity of $\mathbf{2}$ after the structural transformation was different between D- and L-isomer. We expect that this study can provide insights into new rational design strategies for PCPs with chiral recognition.

\section{Acknowledgements}

This work was supported by the JST (Japan Science and Technology Agency), CREST program and a Grant-in-Aid for Scientific Research on Innovative Area "New Polymeric Materials Based on Element-Blocks (No. 2401)" from the Ministry of Education, Culture, Sports, Science and Technology, Government of Japan.

\section{References}

(1) O. M. Yaghi, M. O’Keeffe, N. W. Ockwig, H. K.Chae, M. Eddaoudi, J. Kim, Nature, 423 (2003) 705 .

(2) S. Kitagawa, R. Kitaura, S. Noro, Angew. Chem., Int. Ed. 43 (2004) 2334.

(3) G. Férey, C. Serre, Chem. Soc. Rev. 38 (2009) 1380.

(4) L. J. Murray, M. Dincă, J. R. Long, Chem. Soc. Rev. 38 (2009) 1294.

(5) B. Chen, L. Wang, Y. Xiao, Y. Cui, G. Qian, Angew. Chem., Int. Ed. 48 (2009) 500. 
(6) B. L. Chen, S. C. Xiang, G. D. Qian. Acc. Chem. Res. 43 (2010) 1115.

(7) T. Uemura, N. Yanai, S. Kitagawa, Chem. Soc. Rev. 38 (2009) 1228.

(8) S. Bureekaew, S. Horike, M. Higuchi, M. Mizuno, T. Kawamura, D. Tanaka, N. Yanai, S. Kitagawa, Nature Mater. 8 (2009) 831.

(9) C.-D Wu, A Hu, L Zhang, W Lin, J. Am. Chem. Soc. 127 (2005) 8940.

(10) M. Padmanaban, P. Müller, C. Lieder, K. Gedrich, R. Grünker, V. Bon, I. Senkovska, S. Baumgärtner, S. Opelt, S. Paasch, E. Brunner, F. Glorius, E. Klemm, S. Kaskel, Chem. Commun. 47 (2011) 12089.

(11) Z. Guo, R. Cao, X. Wang, H. Li, W. Yuan, G. Wang, H. Wu, J. Li, J. Am. Chem. Soc. 131 (2009) 6894.

(12) M. Yoon, R. Srirambalaji, K. Kim, Chem. Rev. 112 (2012) 1196.

(13) K. Tanaka, K. Otani, T. Murase, S. Nishihote, Z. U. Lipkowska, Bull. Chem. Soc. Jpn. 85 (2012) 6 .

(14) H. Chun, D. N. Dybstev, H. Kim, K. Kim, Chem. Eur. J. 11 (2005) 3521.

(15) L. Pan, H. Liu, S. P. Kelly, X. Huang, D. H. Olson, J. Li, Chem. Commun. (2003) 854.

(16) R. Kitaura, F. Iwahori, R. Matsuda, S. Kitagawa, Y. Kubota, M. Takata, T. C. Kobayashi, Inorg. Chem. 43 (2004) 6522.

(17) R. Wang, M. Hong, D. Yuan, Y. Sun, L. Xu, J. Luo, R. Cao, A. S. C. Chan, Eur. J. Inorg. Chem. (2004) 37.

(18) M. P. Doyle, W. R. Winchester, M. N. Protopopova, A. P. Kazala, L. J. Westrum, Org. Synth. 73 (1996) 13.

(19) K. Seki, W. Mori. J. Phys. Chem. B 106 (2002) 1380.

(20) D. Dybtsev, H. Chun, K. Kim, Angew. Chem. Int. Ed. 43 (2004) 5033.

(21) J. Greathouse, M. Allendorf, J. Am. Chem. Soc. 128 (2006) 10678.

(22) S. Builes, T. Roussel, C. Ghimbeu, J. Parmentier, R. Gadiou, C. Vix-Guterl, L. F. Vega, Phys. Chem. Chem. Phys. 13 (2011) 16063.

(23) N. Maier, P. Franco, W. Lindner, J. Chromatogr. A. 906 (2001) 3.

(24) K. Suh, M. Yutkin, D. Dybtsev, V Fedin, K. Kim, Chem Commun. 48 (2012) 51 


\begin{tabular}{|c|c|}
\hline Chemical formula & $\mathrm{C}_{31} \mathrm{H}_{32} \mathrm{~N}_{3} \mathrm{O}_{8} \mathrm{Zn}$ \\
\hline Formula mass & 639.98 \\
\hline Crystal system & tetragonal \\
\hline a $(\AA)$ & $21.441(5)$ \\
\hline b $(\AA)$ & $21.441(5)$ \\
\hline c $(\AA)$ & $9.655(2)$ \\
\hline$a\left({ }^{\circ}\right)$ & 90.00 \\
\hline$B\left({ }^{\circ}\right)$ & 90.00 \\
\hline$Y^{\left({ }^{\circ}\right)}$ & 90.00 \\
\hline Unit cell volume & 4438.56 \\
\hline Temperature (K) & 283 \\
\hline Space group & $P 42{ }_{1} 2$ \\
\hline No. of formula units per unit cell, Z & 4 \\
\hline No. of reflections measured & 72144 \\
\hline No. of independent reflections & 2939 \\
\hline$R_{\text {int }}$ & 0.071 \\
\hline Final $\mathrm{R}_{1}$ values $(I>2 \sigma(D))^{\mathrm{a}}$ & 0.086 \\
\hline Final $w R\left(\mathrm{~F}^{2}\right)$ values $\left.(I>2 \sigma(I))\right)^{b}$ & 0.228 \\
\hline Final $R_{1}$ values (all data) & 0.095 \\
\hline Final wR $\left(\mathrm{F}^{2}\right)$ values (all data) & 0.234 \\
\hline Goodness of fit (GOF) on $\mathrm{F}^{2}$ & 1.509 \\
\hline Flack parameter & $0.05(3)$ \\
\hline
\end{tabular}

Flack parameter

${ }^{a} R 1=\left(\left|F_{o}\right|-\left|F_{c}\right| /\left|F_{o}\right|\right)$.

${ }^{\mathrm{b}} \mathrm{wR}_{2}=\left[\mathrm{w}\left(\mathrm{F}_{0}^{2}-\mathrm{F}_{\mathrm{c}}{ }^{2}\right] / \mathrm{w}\left(\mathrm{F}_{0}^{2}\right)^{2}\right)^{1 / 2}$.

Table 1. Crystal data and structure refinement of 2.DMF.

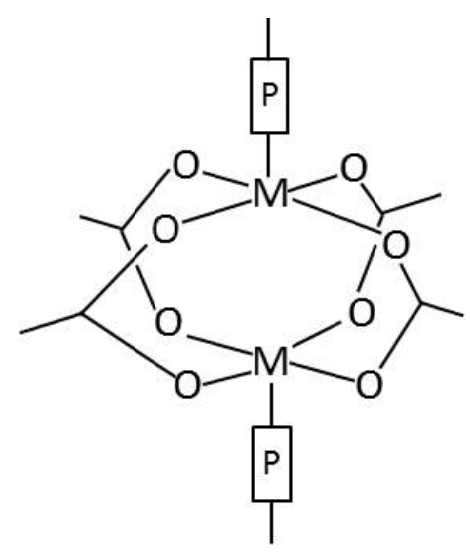

Fig. 1 Bimetal paddlewheel structure (P; pillar ligand). 


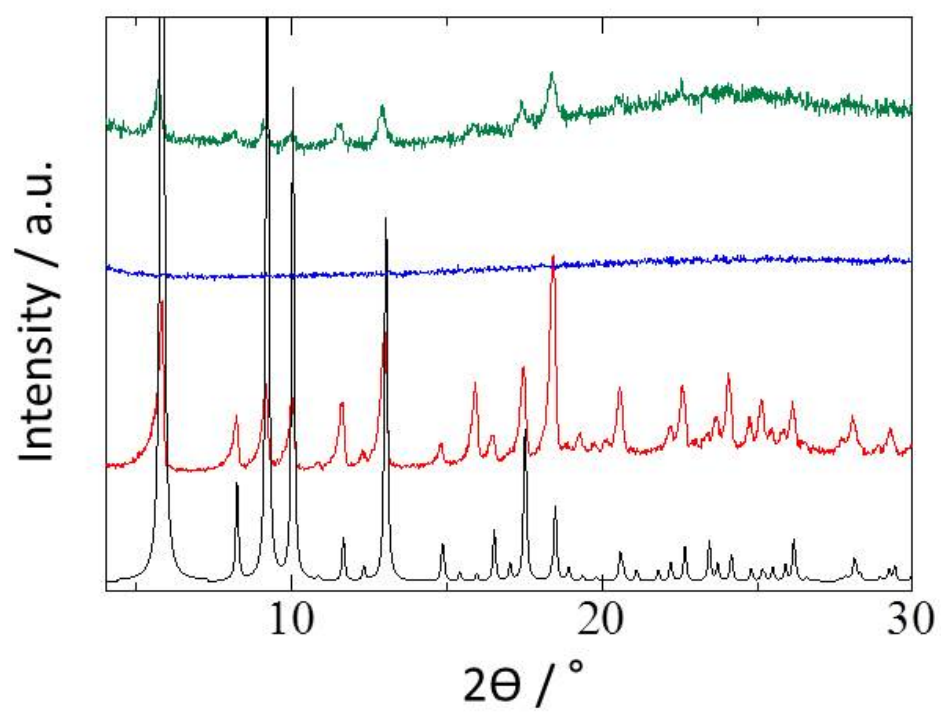

Fig. 2. XRPD patterns of simulated 2 (black), as-synthesized 2 (red), 2' (blue), and 2' after immersing in DMF (green). 
(a)

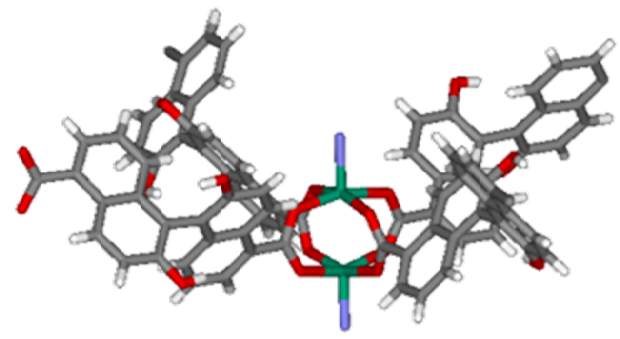

(b)

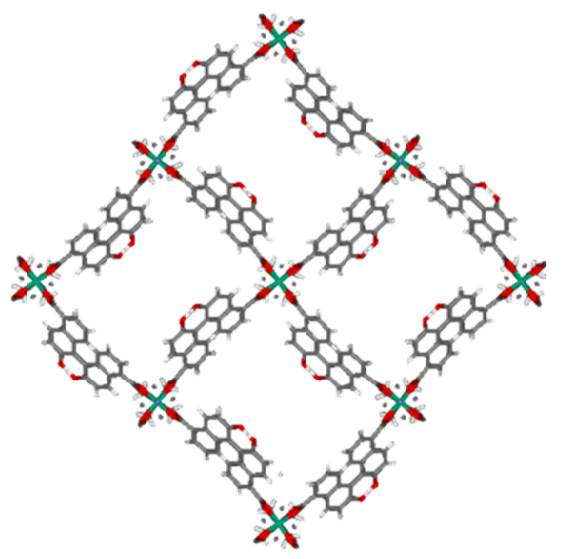

(c)

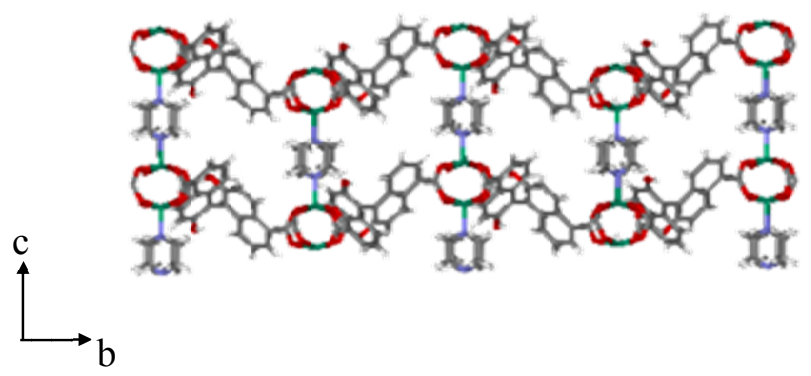

Fig. 3. (a) Coordination environment of $\mathrm{Zn}$ ion and (b) top view and (C) side view of 2.DMF. Legend: Zn: green, O: red, C: grey, N: blue. DMF molecules are omitted for clarity. 


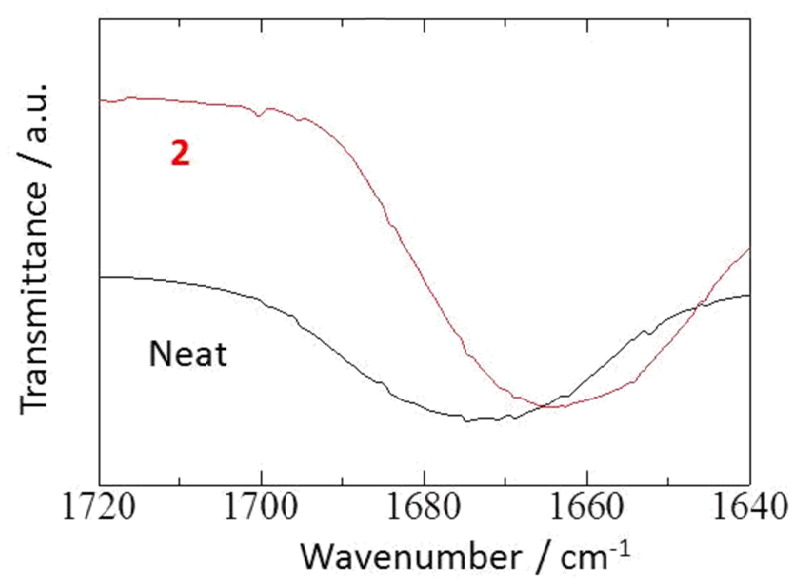

Fig.4. IR spectra of carbonyl group of DMF in 2 (red) and neat (black).
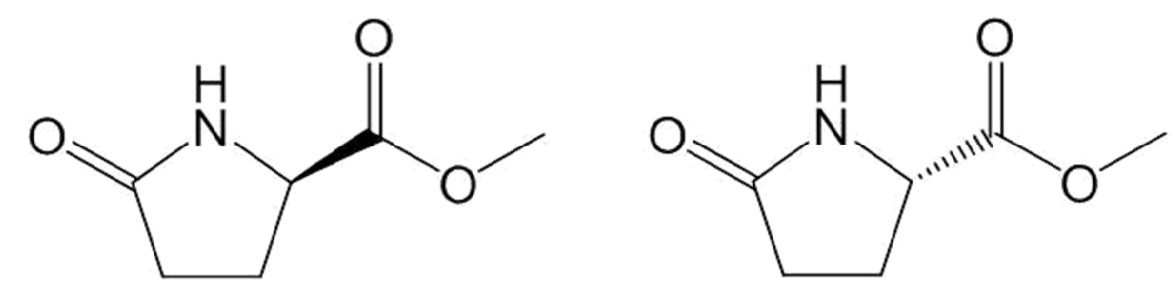

Fig. 5. Molecular structures of methyl pyroglutamate (D-isomer; left, L-isomer; right).

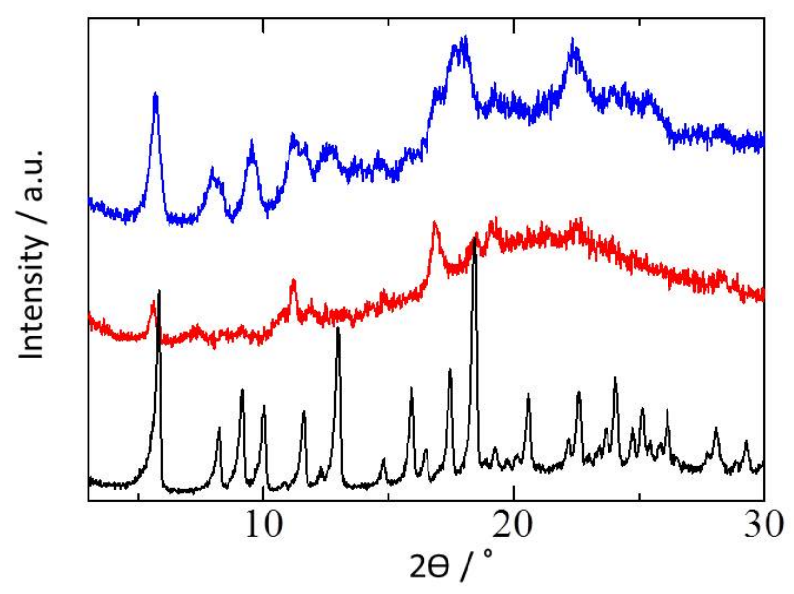

Fig. 6. XRPD patterns of 2 (black), 2. L-isomer (red), and 2. D-isomer (blue). 


\section{Graphical Abstract (Pictogram)}

Synthesis of Chiral Porous Coordination Polymer that Shows Structural Transformation Induced by Guest Molecules

Takashi Kitao, ${ }^{a}$ Yuta Tokunaga, ${ }^{a}$ Daiki Umeyama, ${ }^{a}$ Cho Rong Kim, ${ }^{a}$ Takashi Uemura, ${ }^{a, b}$, and Susumu Kitagawa*a,c

a'Department of Synthetic Chemistry and Biological Chemistry, Graduate School of Engineering, Kyoto University, Katsura, Nishikyo-ku, Kyoto 615-8510, Japan. Fax: +81-753-2732; Tel: +81-753-2733; E-mail:

uemura@sbchem.kyoto-u.ac.jp

${ }^{\mathrm{b}}$ CREST, Japan Science and Technology Agency (JST), 4-1-8 Honcho, Kawaguchi, Saitama 332-0012, Japan. E-mail: uemura@ @bchem.kyoto-u.ac.jp

${ }^{c}$ Institute for Integrated Cell-Material Sciences (WPI-iCeMS), Kyoto University, Yoshida, Sakyo-ku, Kyoto 606-8501, Japan. E-mail: kitagawa@icems.kyoto-u.ac.jp
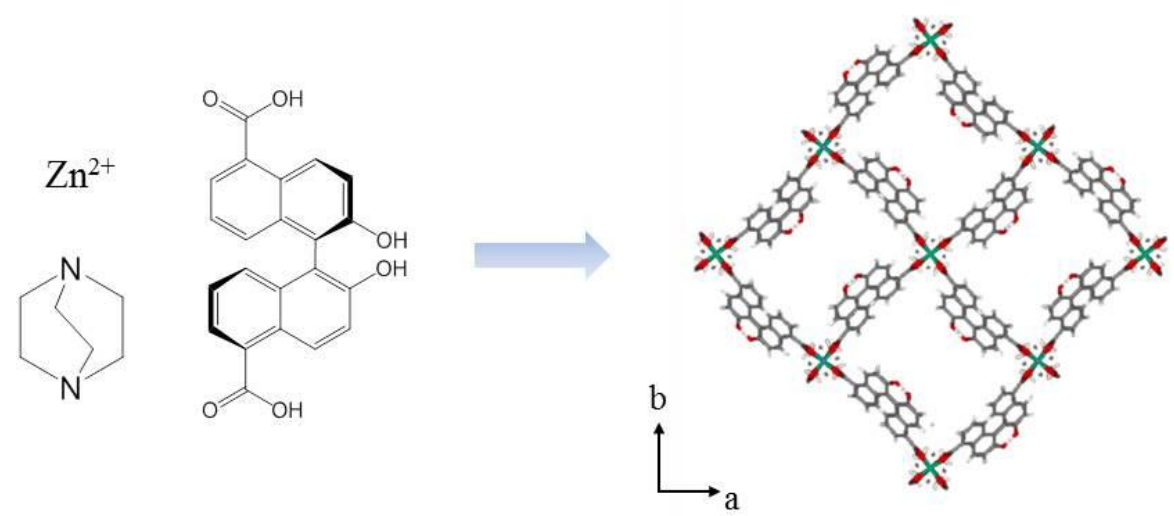